\title{
Uptake and elimination of aromatic hydrocarbons and a chlorinated biphenyl in eggs and larvae of cod Gadus morhua
}

\author{
Jan Erik Solbakken, Snorre Tilseth and Karsten H. Palmork
}

Institute of Marine Research, Nordnesparken 2, N-5011 Bergen, Norway

\begin{abstract}
Artificially fertilized eggs and newly hatched larvae of cod Gadus morhua L. were exposed to ${ }^{14} \mathrm{C}$ labelled naphthalene, phenanthrene, benzo(a)pyrene and $2,4,5,2^{\prime}, 4^{\prime}, 5^{\prime}$-hexachlorobiphenyl (PCB) for $24 \mathrm{~h}$ and thereafter transferred to clean seawater. Radioactivity in eggs and larvae was measured at different times during exposure and after transfer to clean seawater. Maximum accumulation was found with phenanthrene, whereas naphthalene accumulated only slightly in both eggs and larvae. Naphthalene was, on the other hand, rapidly eliminated in contrast to the slow elimination of the other more lipophilic components. Most of the radioactivity accumulated in eggs was transferred to the larvae upon hatching. These findings show that cod eggs and larvae accumulate lipophilic xenobiotics from seawater and that the components will be stored for long time even after eggs and larvae are out of the polluted area.
\end{abstract}

\section{INTRODUCTION}

Marine fish resources are of great economic and nutritional value. Increasing concern is, however, expressed by fishermen and consumers that oil pollution and other worldwide distributed pollutants, like polychlorinated biphenyls (PCB), could be a threat to this renewable food resource. Xenobiotics may affect fish eggs and larvae and result in decreasing recruitment.

In Norway, promising offshore oil fields are situated in the vicinity of spawning grounds of cod Gadus morhua L. The most sensitive periods in the life cycle of marine fishes are the embryonic and larval stages (e.g. Struhsaker, 1977; Lønning, 1977; Kühnhold et al., 1979; Leung and Bulkley, 1979; Linden et al., 1980). Sublethal effects at low levels (40 to $60 \mu \mathrm{g} \mathrm{l}^{-1}$ ) of the water-soluble fraction of crude oil have been demonstrated in larval cod (Tilseth et al., 1981; Solberg et al., $1982 \mathrm{a}, \mathrm{b})$. In an oil spill situation, the hydrocarbon concentration in the upper water layer is quite variable. High concentrations may occur under a drifting oil slick, but as the slick drifts away from a given water mass the concentrations decrease due to mixing and dilution. Thus, we may expect drifting fish eggs and larvae to be exposed to relatively high concentrations of hydrocarbons for relatively short periods. In such situations, the rates of accumulation and elimination of the pollutants will be important factors determining their effects. The present study was performed in order to determine the accumulation and elimination in cod eggs and larvae of some selected hydrocarbons (naphthalene (Nph), phenanthrene (Phe), benzo(a)pyrene (BaP)), as well as a PCB compound $\left(2,4,5,2^{\prime}, 4^{\prime}, 5^{\prime}\right.$-hexachlorobiphenyl, IUPAC no. 153, Ballschmiter and Zell, 1980).

\section{MATERIALS AND METHODS}

\section{Biological material}

Eggs were stripped from ripe ovaries of coastal cod Gadus morhua L. caught north of Bergen, western Norway, in March 1982. The eggs were artificially fertilized in the laboratory and gently washed in clean seawater (34\% S) for $2 \mathrm{~h}$. Dead eggs sank to the bottom and were discarded. After $8 \mathrm{~h}, 10 \mathrm{ml}$ aliquots of eggs were transferred to 10 black 101 plastic aquaria with white bottoms. Antibiotics were administered according to Shelboume (1963), and 2500 IE Mycostatin $1^{-1}$ was also added. These doses were administered only once. The aquaria were placed in a waterbath at $4.5^{\circ} \mathrm{C}$. During incubation, filtered air $10.2 \mu \mathrm{m}$ Millipore filter) was gently bubbled through the aquaria (Tilseth et al., 1981). 


\section{Dosing and sample preparation}

Each of the compounds (Table 1) was dissolved in $100 \mu \mathrm{l}$ of ethanol and mixed with $250 \mathrm{ml}$ UV-sterilized and filtered seawater. Of this, $100 \mathrm{ml}$ was transferred to a $400 \mathrm{ml}$ glass beaker and placed in a waterbath. Experiments were performed with eggs, yolk-sac larvae ( $1 \mathrm{~d}$ old) and $9 \mathrm{~d}$ old larvae, respectively. The yolk is absorbed approximately $8 \mathrm{~d}$ after hatching (Ellertsen et al., 1980). Eggs or larvae $(n=300)$ were gently transferred to each of the experimental beakers. The beakers were aired with filtered air, after which they were sealed with Parafilm and kept in the dark. Then
(Table 2). The initial exposure concentrations for BaP $\left(5 \mu \mathrm{gl}^{-1}\right)$ and PCB $\left(25 \mu \mathrm{g} \mathrm{l}^{-1}\right)$ are above the solubility limits for these components in seawater. However, the components were dissolved in ethanol and thereafter mixed into the seawater thus giving a higher water concentration. Replicates of water samples showed that the concentrations of the components were distributed homogeneously. There were losses in activity during the $24 \mathrm{~h}$ exposure which were considerably greater than the uptakes in the eggs and larvae. No attempt was made to identify these sources of loss in activity. The accumulation of radioactivity in eggs and larvae (Table 3 ) is given relative to the initial concen-

Table 1. Specific activities and molecular weights ( $\mathrm{Mw}$ ) of the ${ }^{14} \mathrm{C}$-labelled xenobiotic compounds used for experiments

\begin{tabular}{|c|c|c|}
\hline Compound & Spec. act. $\left(\mathrm{MBq} \mathrm{mmol}^{-1}\right)$ & $\mathrm{Mw}$ \\
\hline $1(4,5,8)-{ }^{14} \mathrm{C}$ Naphthalene (Nph) & 185 (Amersham) & 130 \\
\hline $9-{ }^{14} \mathrm{C}$ Phenanthrene (Phe) & 714 (Amersham) & 179 \\
\hline 7. $10-{ }^{14} \mathrm{C}$ Benzo(a)pyrene (BaP) & 803 (Amersham) & 253 \\
\hline${ }^{14} \mathrm{C} 2,4,5,2^{\prime}, 4^{\prime}, 5^{\prime}$-Hexachlorobiphenyl (PCB) & 766 (New England Nuclear) & 361 \\
\hline
\end{tabular}

$1 \mathrm{~d}$ exposed eggs or larvae were transferred to $1500 \mathrm{ml}$ clean, aerated seawater $\left(34 \% \mathrm{~S}, 4.5^{\circ} \mathrm{C}\right)$. Samples of seawater $(2 \times 1 \mathrm{ml})$ and of eggs or larvae $(20$ of each per sample) were analysed at various times (Table 3 ). Eggs and larvae were rinsed by successive transfer to 3 vials containing clean seawater to remove radioactivity which adhered to the surface. After addition of Soluene -350 and Dimilume -30 (Packard Instrument) the samples were analysed with a Packard $300 \mathrm{CD}$ scintillation counter.

\section{RESULTS AND DISCUSSION}

Results from radioactivity analyses are given in Tables 2 and 3 . The concentrations of radioactivity in the seawater differed for the various compounds tration in $1 \mu \mathrm{l}$ of the contaminated seawater. The volume of 1 egg or larva is approximately $3 \mu$ (Tilseth, unpubl.). Fig. 1 illustrates uptake and elimination of radioactivity in eggs and yolk-sac larvae expressed as percent of the maximum value obtained.

Uptake of radioactivity was higher with Phe than with the other compounds for both eggs and larvae (Table 3). Lowest uptake in eggs was found with the PCB compound. This corresponds to the higher molecular weight of the PCB as compared to the other compounds (Table 1). The relatively low uptake of the more lipophilic compounds (PCB, BaP) by eggs reflects probably the low lipid content of cod eggs ( 1 to $2 \%$; Riis-Vestergaard, pers. comm.).

The high degree of chlorination of PCB compounds may affect their uptake through the egg case (chorion). Hydrocarbons probably enter the chorion through

Table 2. Concentrations of radioactivity in seawater at start and end of $24 \mathrm{~h}$ exposure in experiments with cod eggs and larvae. Values given as disintegrations $\mathrm{min}^{-1} \mathrm{ml}^{-1}\left(\mathrm{dpm} \mathrm{ml} \mathrm{m}^{-1}\right.$ ), with $\mu \mathrm{gl}^{-1}$ in parentheses

\begin{tabular}{|c|c|c|c|c|}
\hline \multirow[t]{2}{*}{ Compounds } & \multicolumn{2}{|c|}{ Eggs } & \multicolumn{2}{|c|}{ Larvae } \\
\hline & Start & End & Start & End \\
\hline Naphthalene & $1146(14)$ & $999(12)$ & $1759(21)$ & $1375(16)$ \\
\hline \multirow[t]{2}{*}{ Phenanthrene } & 7924 (33) & 4018 (17) & 3607 (15) & 1981 \\
\hline & & & $3311(14)^{\circ}$ & 1852 (8) \\
\hline Benzo(a)pyrene & $996 \quad$ (5) & $411 \quad(2)$ & $1459 \quad(8)$ & $784 \quad(4)$ \\
\hline $\begin{array}{l}2,4,5,2^{\prime}, 4^{\prime}, 5^{\prime} \text { - } \\
\text { Hexachlorobiphenyl }\end{array}$ & $3378 \quad(25)$ & $862 \quad(6)$ & 1219 & $498 \quad(4)$ \\
\hline
\end{tabular}


Table 3. Radioactivity in cod eggs and larvae during and after exposure to naphthalene, phenanthrene, benzo(a)pyrene, and 2, 4, $5,2^{\prime}, 4^{\prime}, 5^{\prime}$-hexachlorobiphenyl. Results are expressed as ratio of $\left(\mathrm{dpm}\right.$ egg $^{-1}$ or larva $\left.^{-1}\right) /\left(\mathrm{dpm}^{\prime} \mathrm{l}^{-1}\right.$ seawater at start of exposure $)$

\begin{tabular}{|c|c|c|c|c|c|c|c|c|c|c|c|c|c|}
\hline \multicolumn{2}{|c|}{ Experiment } & \multicolumn{2}{|c|}{$\begin{array}{l}\text { Exposure } \\
\text { period (d) }\end{array}$} & \multicolumn{10}{|c|}{ Time after transfer to clean seawater (d) } \\
\hline Stage & Compound & 0.1 & 1 & 1 & 2 & 4 & 7 & $\mathrm{bh}^{*}$ & ah $\cdots$ & 10 & 12 & 15 & 20 \\
\hline \multirow[t]{4}{*}{ Eggs } & $\mathrm{Nph}$ & 15 & 18 & 1 & - & 1 & 0 & 0 & 2 & & & & \\
\hline & Phe & 38 & 108 & 129 & - & 79 & 43 & 15 & 9 & & & & \\
\hline & $\mathrm{BaP}$ & 7 & 22 & 29 & - & 22 & 27 & 33 & 25 & & & & \\
\hline & PCB & 4 & 9 & 11 & - & 13 & 12 & 12 & 12 & & & & \\
\hline \multirow[t]{4}{*}{ Yolk-sac larvae } & $\mathrm{Nph}$ & 22 & 23 & 1 & 1 & 1 & 0 & & & 0 & & 0 & - \\
\hline & Phe & 103 & 223 & 150 & 114 & 92 & 74 & & & 39 & & 37 & 21 \\
\hline & $\mathrm{BaP}$ & 10 & 80 & 76 & 61 & 59 & 43 & & & 31 & & 24 & 17 \\
\hline & $\mathrm{PCB}$ & 12 & 93 & 131 & 123 & 147 & 185 & & & 115 & & 108 & - \\
\hline 9 d old larvae & Phe & - & 427 & 195 & 142 & 88 & 69 & & & & 46 & 25 & - \\
\hline $\begin{array}{l}=0.5 \text { to } 1 \mathrm{~d} \text { befo } \\
\because 0.5 \text { to } 1 \mathrm{~d} \text { after }\end{array}$ & $\begin{array}{l}\text { atching } \\
\text { ching }\end{array}$ & & & & & & & & & & & & \\
\hline
\end{tabular}

Fig. 1. Gadus morhua. Uptake and elimination of radioactivity from ${ }^{14} \mathrm{C}$-labelled naphthalene, phenanthrene, benzo(a)pyrene and $2,4,5,2^{\prime}, 4^{\prime}, 5^{\prime}$-hexachlorobiphenyl in eggs (a) and yolk-sac larvae (b). Results expressed as percentages of maximum contents of radioactivity for each compund. Arrows: end of $24 \mathrm{~h}$ exposure; numbers 1 to 20: days in clean seawater
EGGS

(a)

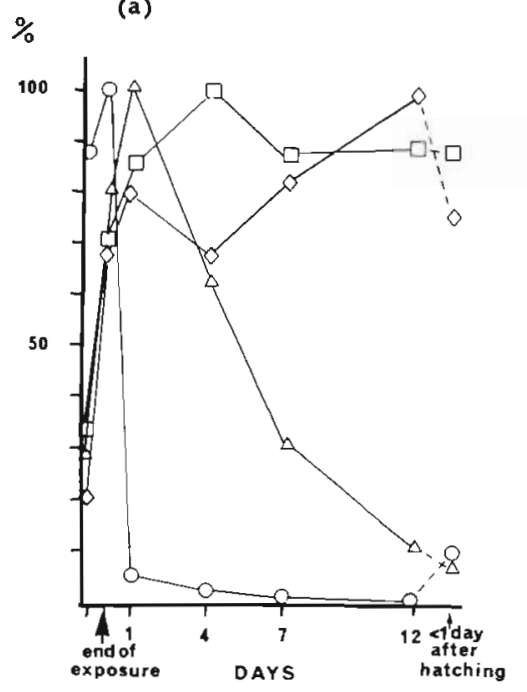

YOLK-SAC LARVAE

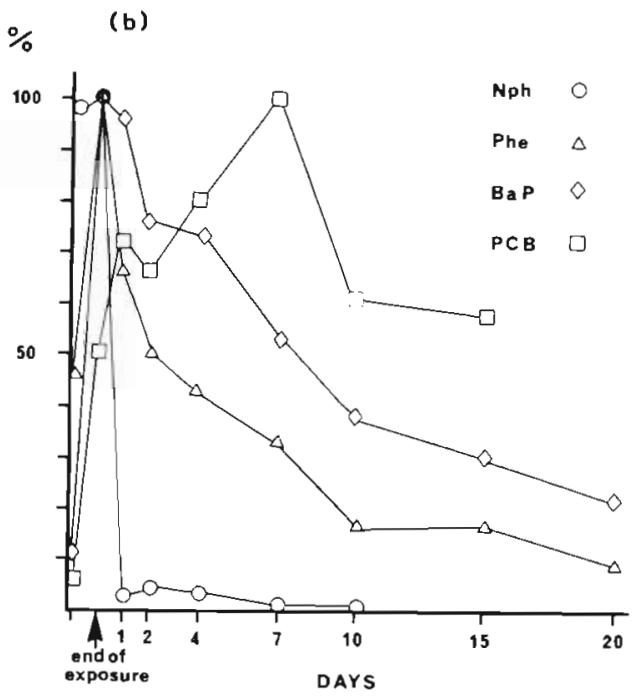

pores, like water. A compound bound to macromolecules in the water may not be able to penetrate the pores in the chorion or the vitelline membrane. During the $24 \mathrm{~h}$ exposure, the larvae accumulated slightly more radioactivity from $\mathrm{Nph}$ and much more from Phe, BaP and PCB than did the eggs (Table 3 ).

In some instances the radioactivity was higher early in the depuration period than at the end of exposure, particularly with the PCB (Fig. 1). This is artificial and reflects variability among the individuals constituting a sample.

The rapid uptake of $\mathrm{Nph}$ in cod eggs is in accordance with results of Kühnhold and Busch (1978) and Sharp et al. (1979). Kühnhold and Busch (1978) found higher accumulation of $\mathrm{Nph}$ than of $\mathrm{BaP}$ in salmon eggs (Salmo salar) after 12 h exposure. With longer incubations, however, the accumulation of BaP gradually exceeded that of Nph. Thus after $7 \mathrm{~d}$ the accumulation factor was $60 \%$ higher for BaP than for Nph. Sharp et al. (1979) reported that the uptake rate of chrysene in eggs of mummichog Fundulus heteroclitus was only $10 \%$ of the uptake of $\mathrm{Nph}$ after $2 \mathrm{~h}$ exposure time.

Samples of chorion and yolk of cod eggs exposed to ${ }^{14} \mathrm{C}$-labelled phenanthrene revealed that most of the radioactivity was associated with the yolk, and not with the chorion (Solbakken, unpubl.). This agrees with Kühnhold and Busch (1978), who found that following exposure of salmon eggs to $\mathrm{Nph}$ and BaP, most of the radioactivity was associated with the vitelline fluid and the yolk. Hose et al. (1982) reported that BaP after $1 \mathrm{~d}$ of exposure accumulated primarily in the yolk-sac of sand sole eggs (Psettichthys melanostichus).

The elimination differed for different xenobiotic 
components (Fig. 1). Nph was rapidly eliminated from eggs and larvae while Phe was more slowly eliminated. There was no apparent elimination of $\mathrm{BaP}$ and PCB from eggs, and high concentrations of radioactivity remained $12 \mathrm{~d}$ after transfer to clean seawater. Radioactivity from all components was transferred to larvae upon hatching (Fig. 1a). The high content of radioactivity in newly hatched larvae is further evidence that most of the radioactivity in eggs prior to hatching was associated with the yolk or embryo.

$\mathrm{Nph}$ is more water soluble than the other components; this may explain its rapid uptake by eggs and larvae. Rapid elimination of $\mathrm{Nph}$ from eggs and larvae can also be explained in terms of the low lipid/water partition coefficient and the high aqueous solubility of $\mathrm{Nph}$. Although Nph has a high affinity for lipids, its lipid/water partition coefficient favours rapid release to water when the Nph concentration in the medium is reduced (Neff, 1979).

As for the eggs, there was no apparent elimination of PCB from yolk-sac larvae (Fig. 1b). In contrast, there was a clear elimination of BaP-derived radioactivity. This may indicate higher activity of enzymes capable of metabolizing aromatic hydrocarbons in yolk-sac larvae than in eggs. Thus, Sharp et al. (1979) found no metabolism of $\mathrm{Nph}$ and chrysene in mummichog embryos. The elimination of $\mathrm{Nph}$ and Phe from the eggs in the present study, may be a result of water transport across the chorion, in spite of low water exchange across the cellular membrane of cod eggs as compared to other biological membranes (Riis-Vestergaard, pers. comm.). The results reported by Sharp et al. (1979) indicate decreasing permeability of the embryonic cellular membrane to Nph during development. The cellular membrane is thought to represent the main barrier to diffusion of water and solutes between the medium and the embryonic tissues (Potts and Eddy, 1973). Such a decrease in permeability would presumably not have affected the elimination of Nph-derived compounds from the eggs in the present study, since most of the radioactivity was eliminated during the first $24 \mathrm{~h}$. For Phe, $\mathrm{BaP}$ and $\mathrm{PCB}$, a change in the permeability can have influenced their elimination and this may partly explain the high levels of radioactivity remaining during the depuration period in these studies.

The fates of Nph, Phe, BaP and PCB in cod larvae are in general agreement with results obtained for the same compounds in experiments with adult flounders Platichthys flesus (Solbakken et al., 1983). Also in flounder the highest accumulation was found with Phe, whereas Nph was most efficiently eliminated. Only a slight elimination of PCB derived radioactivity occurred during $70 \mathrm{~d}$ of depuration.

The $9 \mathrm{~d}$ old larvae which had absorbed their yolk- sacs accumulated approximately twice as much Phe as the yolk-sac larvae, but the elimination was more efficient (Table 3). This shows that the more advanced physiological development resulted in a higher uptake and indicates a higher enzymatic capacity for metabolizing aromatic hydrocarbons. In newly hatched larvae the mouth is not opened, preventing intragastric uptake of contaminated seawater.

We did not attempt to study the effects of the aromatic components on eggs and larvae. However, the survival of yolk-sac larvae in experimental beakers give some indication as to the toxicity. Thus only 3 larvae were alive $15 \mathrm{~d}$ after transfer to clean seawater in the PCB study, whereas more than 20 survived in each of the other experiments.

Eggs and larvae from the same parent fish as in the present study have been used to study behavioral and physiological effects of low levels of the water-soluble fraction and a fraction with boiling point $>150^{\circ} \mathrm{C}$ of Ekofisk crude oil (Solberg et al., 1982a, b). These results show that cod larvae exposed to oil contaminated seawater exhibited retarded growth, decreased oxygen consumption rate and reduced ability to capture prey. These clear effects at relatively low oil concentrations may be related to our present findings of low elimination rates of aromatic hydrocarbons from the larvae.

According to our results aromatic hydrocarbons in the environment can easily be accumulated in eggs and larvae of cod, the degree of uptake being dependent on the molecular weight and/or lipophilic characteristics of the xenobiotics. The chorion appears to serve as a barrier for molecules such as PCB's, probably because the hydrocarbons are chlorinated and/or bound to macromolecules or particles in the water. Eggs and young larvae of cod are planktonic and their distribution is patchy and dependent on the hydrographic conditions (Ellertsen et al., 1981). It is likely that fish eggs and larvae will come in contact with relatively high concentrations of xenobiotic components for a short time only. Our results show that even if the exposure time is short, lipophilic xenobiotic components will accumulate and follow eggs and larvae during their development. The high uptake rates and low elimination rates of lipophilic xenobiotics in eggs and larvae may explain the increased toxicity of pollutants in the early part of the cod's life.

Acknowledgements. We thank H. R. Skjoldal, Institute of Marine Research, Bergen and P. Sayre, Georgetown University, Washington for reviewing the manuscript and J. Pereira for typing. A. Sæeverud analysed the samples. This investigation was sponsored by the Norwegian Marine Pollution and Monitoring Programme. 


\section{LITERATURE CITED}

Ballschmiter, K., Zell, M. (1980). Analysis of polychlorinated biphenyls (PCB) by glass capillary gas chromatography. Composition of technical aroclor- and clophen-PCB mixtures. Fresenius Z. Anal. Chem. 302: 20-31

Ellertsen, B., Moksness, E., Solemdal, P., Strømme, T., Tilseth, S., Westgård, T., Øiestad, V. (1980). Some biological aspects of cod larvae (Gadus morhua L.). FiskDir. Skr., Ser. HavUnders. 17: 29-47

Ellertsen, B., Solemdal, P., Strømme, T., Sundby, S., Tilseth, S., Westgård, T. (1981). Spawning period, transport and dispersal of eggs from the spawning area of arcto-norwegian cod (Gadus morhua L.). Rapp. P.-v. Réun. Cons. int. Explor. Mer 178: 260-267

Hose, J. E., Hannah, J. B., DiJulio, D., Landolt, M. L., Miller, B. S., Iwaoka, W. T., Felton, S. P. (1982). Effects of benzo(a)pyrene on early development of flatfish. Arch. environ. Contam. Toxicol. 11: 167-171

Kühnhold, W. W., Busch, F. (1978). On the uptake of the three different types of hydrocarbons by salmon eggs (Salmo salar L.). Meeresforsch. 26: 50-59

Kühnhold, W. W., Everich, D., Stegeman, J. J., Lake, J., Wolke, R. E. (1979). Effects of low levels of hydrocarbons on embryonic, larval and adult winter flounder ( $P$ seudopleuronectes americanus). In: Bates, C. D. (ed.) Proc. of conf. on ass. of ecol. imp. of oil spills. Keyst. Colorado, 14-17 June 1978. Arlington, Va., p. 677-711

Leung, T. S., Bulkley, R. V. (1979). Effects of pectroleum hydrocarbons on length of incubation and hatching success in the Japanese Medaka. Bull. environ. Contam. Toxicol. 23: 236-243

Linden, O., Laughlin, R. B., Sharp, J. R., Neff, J. M. (1980). The combined effect of salinity, temperature and oil on the growth pattern of embryos of the killifish Fundulus heteroclitus Walbaum. Mar. environ. Res. 3: 129-144
Lønning, S. (1977). The effects of crude Ekofisk and oil products on marine fish larvae. Astarte 10:37-47

Neff, J. M. (1979). Polycyclic aromatic hydrocarbons in the aquatic environment. Applied Science Publishers Ltd., London

Potts, W. T W., Eddy, F. B. (1973). The permeability to water of the eggs of certain marine teleosts. J. comp. Physiol. 82: 305-315

Sharp, J. R., Fucik, K. W., Neff, J. M. (1979). Physiological basis of differential sensitivity of fish embryonic stages to oil pollution. In: Vernberg, F. J., Vernberg, W. B., Calabrese, A. (ed.) Marine pollution: functional responses. Academic Press, New York, p. 85-108

Shelbourne, J. E. (1963). A marine fish-rearing experiment using antibiotics. Nature, Lond. 198: 74-75

Solbakken, J. E., Solberg, M., Palmork, K. H. (1983). A comparative study on the disposition of three aromatic hydrocarbons in flounder (Platichthys flesus). FiskDir. Skr., Ser. HavUnders. 17

Solberg, T. S., Tilseth, S., Jensen, A. W., Serigstad, B., Westrheim, K. (1982a). Effects of low levels of Ekofisk crude oil on eggs and yolksac larvae of cod (Gadus morhua L.). Coun. Meet. int. Coun. Explor. Sea E 60: 1-18

Solberg, T, S., Tilseth, S., Serigstadt, B., Westrheim, K. (1982b). Effects of low levels of the heavy fraction of Ekofisk crude oil on eggs and yolksac larvae of cod (Gadus morhua L.). Coun. Meet. int. Coun. Explor. Sea E 59: 1-13

Struhsaker, J. W. (1977). Effects of benzene (a toxic component of petroleum) on spawning Pacific herring, Clupea harengus pallasi. Fish. Bull. U.S. 75: 43-49

Tilseth, S., Solberg, T. S., Westrheim, K. (1981). Sublethal effects of the water-soluble fraction of Ekofisk crude oil on the early larval stages of cod (Gadus morhua L.). Coun. Meet. int. Coun. Expor. Sea E 52: 1-21 